\title{
Peak Load Modeling for Kingdom of Bahrain
}

\section{Isa S Qamber}

Deanship of Scientific Research, University of Bahrain, P. O. Box 32038, Isa Town, Kingdom of Bahrain.

Email: iqamber@uob.edu.bh

Received 2012

\begin{abstract}
Deriving some models to estimate the electrical demand for future for the Kingdom of Bahrain is carried out in the present study. The ambient temperature is taken into the account as well as the time factor (Year). The model was developed in away describing the electric power demand during a summer period. The estimated values of the maximum electrical load is obtained and evaluated on actual peak load data of the Kingdom of Bahrain.
\end{abstract}

Keywords: Peak Load; Curve Fitting; Maximum Annual Load

\section{Introduction}

Electricity systems models are software tools used to manage electricity demand and the electricity systems and for generation expansion planning purposes. Various portfolios and scenarios mentioned later in the literature review are modeled in order to compare the effects of decision making in policy and on business development plans in electricity systems. The modeling techniques developed to study vertically integrated state monopolies are now applied in liberalized markets where the issues and constraints are more complex. This paper reviews the modeling response to key developments. The paper provides an overview of electricity systems modeling Kingdom of Bahrain.

\section{Literature Review}

Through the literature review there are several articles discussing load modeling by using different techniques. Linear regression models have been widely used.

Annual maximum power load models are software tools used to manage electrical load demand. These models are used to help the engineers and managers for generation expansion planning purposes. A number of scenarios are tested and modeled in order to be compared and tested to reach a suitable decision.

Peik-Herfeh etl al in their article [1] which will be published in the year 1213 present the improvements in renewable energy technologies which are used in the resources. A number of factors are considered where portions of electrical demand have been met. A virtual power plane is decentralized energy management system tasked to aggregate the capacity of some Distributed Generations, storage facilities, and Dispatchable for the purpose of energy trading and/or providing system support services. Due to the stochastic behavior of the prime sources of some Distributed Generations, such as wind speed and temperature, the steady state analysis of the systems with integration of such Distributed Generation units requires a probabilistic approach.

Orlando et al in their paper [2] studied the electric energy prices in Brazil. The electric energy prices are higher during $3 \mathrm{~h}$ of peak consumption on working days. However, consumers could use a generator system for partially reducing the electricity costs from utility company during peak hours. The process of sizing a generator system begins developing the so called load capacity curve. The acquired building electricity consumption data was used. This authors in their paper developed two methodologies to estimate the curve for every month of the year. The first method use the frequency of occurrence of the measured values of the load power as supplied by the local utility monthly bills. Finally a generator system was sized, minimizing the electrical energy cost supplied by it, when the generator meets partially the building load.

Kaldellis et al in their paper [3] considering on the basis of probability distribution of the load demand of a representative Greek island and the corresponding data related to the available wind potential. In their study estimates the maximum - acceptable by the local grid wind energy contribution. For that reason, an integrated computational algorithm has been developed from first principles, based on a stochastic analysis. Based on the results obtained, it becomes evident that with the current wind turbine technology, wind energy cannot play a key role in coping with the electrification problems encountered in many Greek island regions, excluding however the case of introducing bulk energy storage systems that 
may provide considerable recovery of the remarkable wind energy rejections expected.

Niknam et al [4] in their paper they used the green energies and rising concerns about high cost of energy from fossil fuels, renewable energy sources appears to be a promising approach for producing local, clean, and inexhaustible energy. This motivates the implementation of microgrids introduced as a cluster of electrical and/or thermal loads and different, renewable energy sources. Due to different uncertainties linked to electricity supply in renewable microgrids, probabilistic energy management techniques are going to be necessary to analyze the system. The authors in their paper proposes a probabilistic approach for the energy and operation management of renewable Microgrids under uncertain environment. The authors in their paper considered uncertainties in load demand, market prices and the available electrical power of wind farms and photovoltaic systems.

Tawalbeh et al [5] in their paper presented a nonlinear approach to estimate the consumed energy in distribution feeders. The proposed method uses the statistical solution algorithm to analyze the active energy monthly consumption, which enables one to estimate the energy consumption during any period of the year. The energy readings and the normalized accumulated energy profile are used to estimate the hourly consumed active power, which can be used for future planning and sizing the equipment of the electrical system. The effectiveness of the proposed method is demonstrated by comparing the simulated results with that of real measured data.

Qader and Qamber in their paper [6] developed a model for load estimation of Kingdom of Bahrain. The calculation method involves a Monte Carlo technique for the simulation of the load. The model enables the predication of the load against the time during years, where each year is divided into 52 weeks. The forecasting model, computes minimum mean square error (MMSE) forecasts of the conditional mean of reserve power and conditional standard deviation of the innovations in each period over a user specified forecast possibility. To do this, it views the conditional mean and variance models from a linear filtering perspective, and applies iterated conditional expectations to the recursive equations, one forecast period at a time. The results are obtained and discussed.

Three scenarios have been carried out by Qamber [7] to calculate the predicted maximum annual load for the kingdom of Bahrain with the objective of formulating an expansion plan for a future generating system. The results of the three scenarios were obtained and compared using a comprehensive analysis. The maximum annual load was calculated at average rates of $6.79 \%$ in the more reasonable scenarios using the MATLAB package following the curve-fitting polynomial technique.

\section{Results and Discussions}

It is well known that the electrical power demand is linked to several weather variables, mainly the air temperature. The present work concentrates on the effect of the annual maximum temperature plus the population to the electric load demand in Bahrain. A number of models are derived which allowed a better characterization of the observed modeling relationships. The models which are designed to forecast the load's behavior should be able to show the effect of the considered factors. Temperature has a great effect on the hourly energy consumption.This effect first of all causes the annual maximum change in the consumption load curve in a way that the curve is higher for a hot summer day than a colder day and vice-versa.

For electric power load forecasting, the accurate models are essential to operation and planning of utility. Furthermore, a particular network is possible to predict the next year maximum load. It is well known that it is impossible to predict the next year maximum load with high accuracy as the next day load. The next day load can be predicted with an accuracy of 1-3\%.

Table 1 reproduced from the previous study carried out by Qamber [7], the only difference that the population of Kingdom of Bahrain is added to the Table.

In Figure 1 the relation between the maximum annual actual load versus years in Bahrain, as it shows that the load increased in the years 2009, 2010 and 2011. The load decreased in the year 2011, because the maximum temperature during year 2011 was less than the previous year increasing. The formula for such figure is as follows:

$$
\operatorname{Load}_{\mathrm{AcP}} \quad(\chi)=132.5 * \mathrm{x}-263743
$$

where: $\operatorname{Load}_{\mathrm{AcP}}(\chi)$ is the higher actual peak load (MW)

$$
\chi \text { is the year }
$$

The operating maximum peak load for Kingdom of Bahrain can be found by substituting the year into Equation (1) to find out the estimated maximum peak load for the substituted value of the year. The data for the present study are taken from a study done by Qamber [7].

Table 1. Historical data for kingdom of bahrain.

\begin{tabular}{cccc}
\hline Year & $\begin{array}{c}\text { Maximum } \\
\text { Temperature (C) }\end{array}$ & $\begin{array}{c}\text { Actual Peak } \\
\text { Load (MW) }\end{array}$ & $\begin{array}{c}\text { Population } \\
(\mathrm{k})\end{array}$ \\
\hline 2009 & 45.7 & 2437 & 1178.415 \\
2010 & 47.4 & 2708 & 1228.543 \\
2011 & 45.9 & 2500 & 1224.571 \\
2012 & 45.7 & 2948 & 1248.348 \\
\hline
\end{tabular}

Figure 2 illustrates the variation combination of the maximum temperature (C) and actual peak load (MW) 
versus the years from 2009 and 2012 through the histogram.

Figure 3 shows the relation between the population in Bahrain versus years. It shows that the population increased year after year. The model obtained for such a type of data is as follows:

$$
\text { Population } \quad(\chi)=21582.7 * x-42169549
$$

where: Population $(\chi) \quad$ is the Population in Bahrain

$$
\chi \quad \text { is the year }
$$

Figure 4 illustrates the histogram of the maximum temperature $\left({ }^{\circ} \mathrm{C}\right)$ versus years from 2009 and 2012.

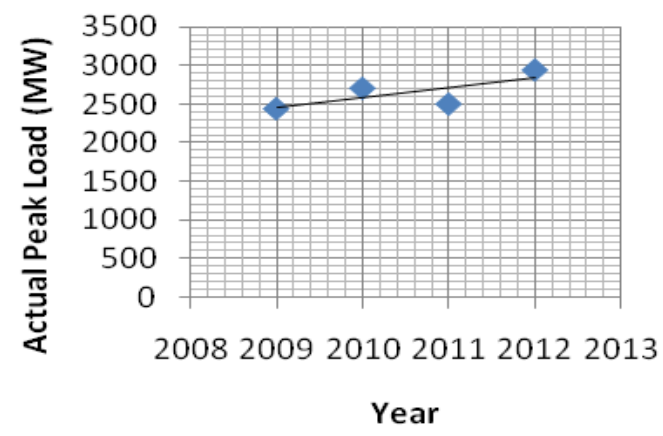

Figure 1. Relationship between Peak Load and Year.

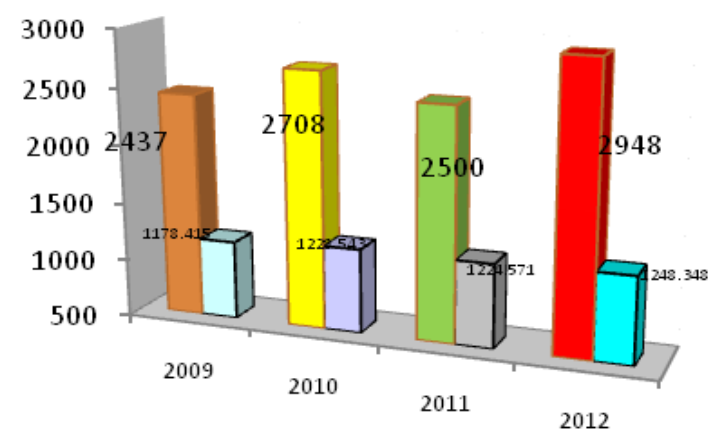

Figure 2. The Histogram showing the combination of Maximum Temperature and actual Peak Load versus Years.

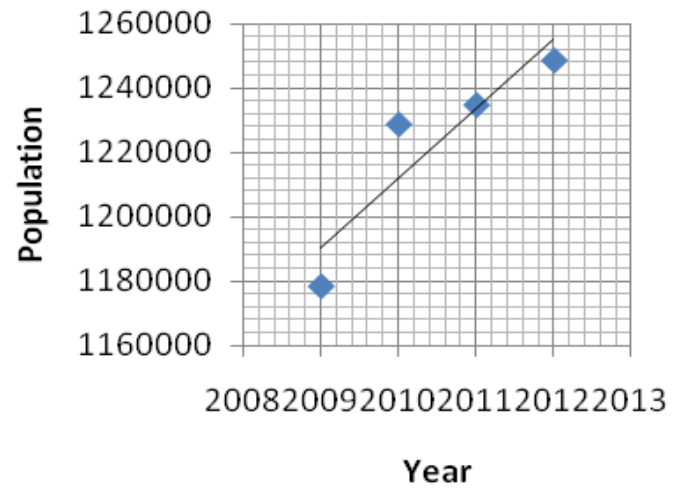

Figure 3. Relationship between Population and Year.

Figure 5 shows the relation between the actual peak load and the population in Bahrain through the years
2009 and 2012. It shows that the population increased year after year; where the annual load increased in three years 2009, 2010 and 2012. The model obtained for such a type of data is as follows:

Load $_{\text {AcP }}$

$($ Population $)=0.0055953443 *$ Population -4191.8864

where: $\operatorname{Load}_{\mathrm{AcP}}$ (Population) is the higher actual peak load (MW)

Population is the Population in Bahrain

Table 2 illustrates the variation of actual peak loads (2009-2012) plus estimated values (2013-2015) versus years.

Figure 6 shows the relation between the actual peak loads for the years (2009-2012) plus the estimated highest values annual maximum load for the years (20132015) obtained by Qamber [7] versus years in Bahrain. The model obtained for such a type of data is as follows:

$\operatorname{Load}_{\text {EHLoad }}($ Year $)=198.07143 *$ Year -395554.43 (4)

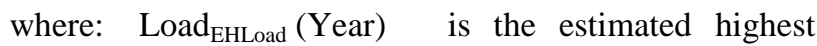
load (MW) Year

is the Year

Table 3 illustrates the relationship between Maximum Loads versus Years.

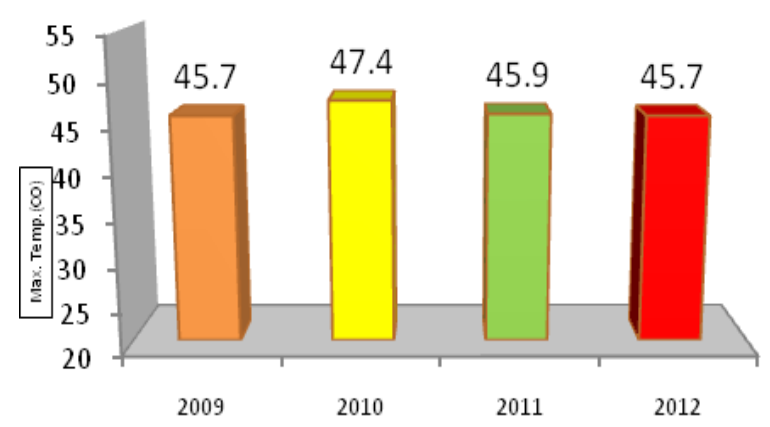

Figure 4. The Histogram showing the Maximum Temperature versus Years.

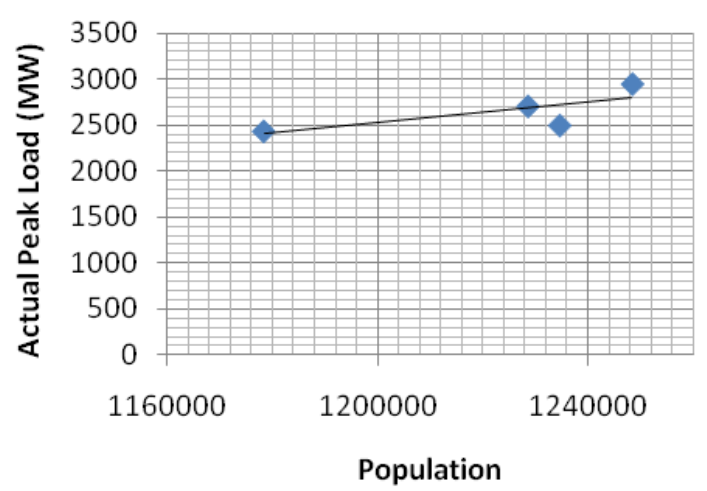

Figure 6. The Relationship between the Load versus Years.

Figure 7 shows the relation between the actual peak maximum loads for the years (2009-2012) plus the esti- 
mated maximum values of the annual load for the years (2013-1015) - obtained in the present study from the graph represented by Figure 7 - versus years in Bahrain. The model obtained for such a type of data is as follows:

$$
\operatorname{Load}_{\text {EMLoad }}(\text { Year })=132.5 * \text { Year }-263743
$$

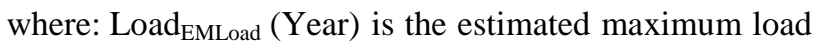
(MW)

$$
\text { Yea is the Year }
$$

In this paper the linear regression analysis of Bahrain's electrical load recognizes that the load pattern is heavily dependent on ambient temperature, and finds a linear function between the load and the temperature. The mathematical model of the temperature dependency describes the increase in annual load when ambient temperature changes.

Table 2. Peak Loads versus years.

\begin{tabular}{cc}
\hline Year & Load (MW) \\
\hline 2009 & 2437 \\
2010 & 2708 \\
2011 & 2500 \\
2012 & 2948 \\
2013 & 3168 \\
2014 & 3383 \\
2015 & 3613 \\
\hline
\end{tabular}

Table 3. Maximum Loads versus Years.

\begin{tabular}{cc}
\hline Year & Load (MW) \\
\hline 2009 & 2437 \\
2010 & 2708 \\
2011 & 2500 \\
2012 & 2948 \\
2013 & 2979.5 \\
2014 & 3112 \\
2015 & 3244.5 \\
\hline
\end{tabular}

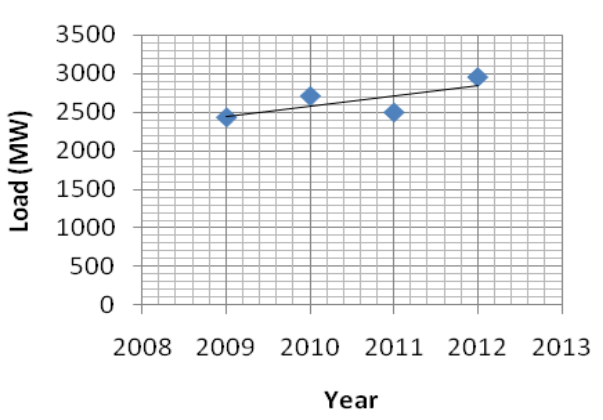

Figure 7. Relationship of the loads versus years.

The curve fitting and modeling techniques are helping and advising for the best solution and approach to reach the suitable model. The present paper highlights on the previous studies with the software used in each study plus the models built in one of them and tested I the present study to reach the best solution.

\section{Conclusions}

In this paper, a simple and accurate models are discussed earlier for annual maximum load and efficient algorithms. The coefficients for each model are calculated. The input parameters of the models are the historical maximum annual loads, maximum ambient temperatures and population in the Kingdom of Bahrain. In the present study, it is clear how much the weather conditions (ambient temperature) influence the load. The models obtained in the present study considering and developing an algorithm for the annual peak loads.

\section{Acknowledgements}

The author would like to express his thanks to the University of Bahrain for the preparation of the facilities to make this research possible.

\section{REFERENCES}

[1] M. Peik-Herfeh, H., Seifi and M.K. Sheikh-El-Eslami, "Decision making of a virtual power plant under uncertainties for bidding in a day-ahead market using point estimate method", International Journal of Electrical Power and Energy Systems, Vol. 44, No. 1, 2013, pp. 88-98.

[2] A. F. Orlando, M. P. Málaga, M.M. Huamani, "Methodology for generating electric load profiles for sizing an electric energy generation system”, Energy and Buildings, Vol. 52, 2012, pp. 161-167.

[3] J. K. Kaldellis, M. Kapsali, and D. Tiligadas, "Presentation of a stochastic model estimating the wind energy contribution in remote island electrical networks”, Applied Energy, Vol. 97, 2012, pp. 68-76.

[4] T. Niknam, F. Golestaneh and A. Malekpour, "Probabilistic energy and operation management of a microgrid containing wind/photovoltaic/fuel cell generation and energy storage devices based on point estimate method and self-adaptive gravitational search algorithm”, Energy, Vol. 43, No. 1, 2012, pp. 427-437.

[5] N. Tawalbeh and R. El-Khazali, "Peak load evaluation based on the accumulated annual energy", Proceedings of the $16^{\text {th }}$ IEEE Mediterranean Electrotechnical Conference, MELECON 2012;Yasmine Hammamet; 25-28 March 2012, Article number6196492, pp. 544-547.

[6] M.R. Qader and I. Qamber, "Enhancement, evaluation and implementation of a load forecasting method", JAAUBAS, Vol. 11, April 2012, pp. 1-8.

[7] I. Qamber, "Maximum Annual Load Estimation and Network Strengthening for the Kingdom of Bahrain”, AGJSR, Vol. 28, No. 4, 2010, pp. 214-223. 